\title{
OBITUARY
}

\section{Arthur Robert von Hippel (1898-2003)}

When I was an MIT student in the late 1960s, "the Prof", as he was lovingly called, was still well known for his outstanding pioneering research in dielectrics, molecular science and molecular engineering, despite being formally retired from MIT.As I was finishing up my doctoral thesis research in 1969-70, I experienced for myself Prof. Von Hippel's reputation as "a great scientist, great lecturer, and a great man", as he was described by Maurizio Vallauri, a member of Von Hippel's MIT Laboratory for Insulation Research in 1954-55. Von Hippel offered a two-term course entitled "From atoms to living systems", and as part of the course, I met with him weekly to discuss physics. His long-time secretary, Aina Sils, served cookies and tea. His lectures included many slides where history would slip in, such as a picnic scene with a dignitary such as Albert Einstein, followed by an anecdote.

Von Hippel has an inspiring life story. He was involved in both World Wars, and had to leave Hitler's Germany because of his Jewish wife Dagmar, who was the daughter of the Nobel prize winner James Franck. With the rising tide of antiSemitism and the coming of the Nazis, marrying a Jew was risky, but von Hippel had taken a stand as an anti-Nazi. He wrote a counter declaration for the Youth Movement, for which he had taken a pledge to live a life of purity, responsibility and mutual helpfulness. The Youth Movement's emphasis on friendship and involvement in outdoor activities also guided von Hippel's life - he was crosscountry skiing up to age 95 , and walking a milea day even into his 100 s.

Von Hippel served in World War I as an army private. After the war, he studied subjects from classical physics to quantum mechanics at the University of Göttingen, then a "Centre of the Scientific Revolution". Convinced that theoretical physics was a calling reserved for geniuses, he instead became a PhD student in the more practical Institute for Applied Electricity. He finished his thesis in 1924, having designed and built a new type of thermo-microphone that allowed transmission of radio broadcasts free from frequency distortion. After a period working as Max Wien's assistant in Jena, he took a oneyear Rockefeller fellowship in 1927 at the University of California at Berkeley. Von Hippel's European schooling and early professional life put him in close association with many of the major leaders in physics, including Bohr, Sommerfeld, Heisenberg, Wien, Courant, Debye, Born, Franck, Hertz, Hilbert, Pohl, Pauli, and in America with Loeb, Oppenheimer and Einstein.

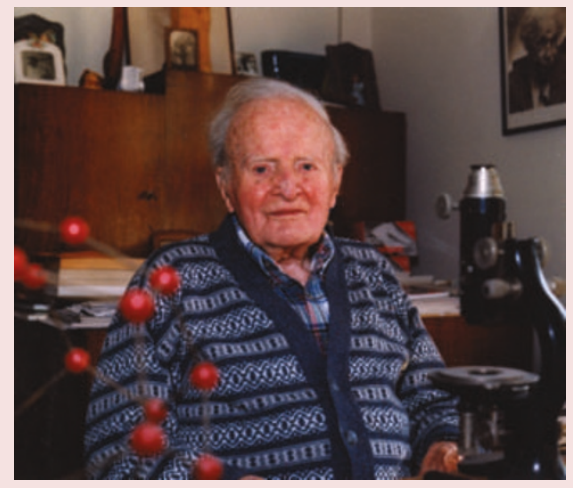

\section{PROFESSOR ARTHUR ROBERT VON HIPPEL AT AGE 100. PHOTO/LINDA ZAHN}

Karl Compton offered von Hippel an MIT faculty position in 1936 to become "the physicist of the Electrical Engineering Department”. His starting salary was about $\$ 3,500$ per year — so small that when his three boys were in hospital with infections, he had to sell his Handbook of Physics to pay the bill. Professional jealousies at MIT meant that he required the testimony of his students to prove that he did not mistreat them, and he had to give a colloquium to demonstrate that his pronunciation was understandable. In 1939 , with a grant of $\$ 5,000$, von Hippel founded the Laboratory for Insulation Research (LIR), breaking away from classical engineering concepts and departmental constrictions. The name was chosen to justify having a group of physicists and chemists in an electrical engineering department, and also avoided intruding on other people's interests. But this name proved to be much too narrow, and the LIR became internationally renowned as one of the first interdisciplinary laboratories in the field of modern materials research.

With US entry into WWII, there were rumours that von Hippel was a spy, but these were quickly dispelled when he gained US citizenship in 1942. The LIR was responsible for the development, measurement, commercial manufacture and technical applications of radar dielectrics. In recognition of "outstanding services to his country," von Hippel was awarded the second highest civilian award, the President's Certificate of Merit, in 1948. One of his notable discoveries was that of ferroelectricity and piezoelectricity in barium titanate in 1944.
Von Hippel wrote three books that transformed materials research into the molecular design of materials and devices: Dielectrics and Waves; Dielectric Materials and Applications; and Molecular Science and Molecular Engineering . Even today, his Table of Dielectric Materials is the first source for researchers looking for values of the dielectric constant and conductivity of materials.

The LIR educated about 60 doctoral students, 47 masters students, a large number of students completing bachelors theses, and numerous post-doctoral researchers from all over the world. Von Hippel loved music, and laboratory members formed a string quartet to play on special occasions, such as at LIR organized meetings and dinners. There were also ice-cream and apple pie affairs on occasions when von Hippel needed a break from work and took whoever was available to an ice-cream shop across the street from the Lab. Von Hippel was a father-figure and mentor to all in the Lab, and worked at MIT well into his eighties. At the time of his official retirement in 1964, LIR had about 70 members in eight research groups, which helped form the MIT Center for Materials Science and Engineering.

Von Hippel was the recipient of the inaugural Material Research Society award for excellence in the field of materials research in 1977. The award was then named after him with the citation "In whose honor the premier award of the Materials Research Society is named, was a pioneer in the study of dielectrics, semiconductors, ferromagnetics, and ferroelectrics." He was an early advocate of the interdisciplinary approach to materials research, and his example substantially furthered the science of materials.

Von Hippel's last productive years were concerned with the question: how does nature proceed with its design in creating living systems? Von Hippel was interested in the ingenious way in which nature uses water as a solvent, reactant and structuring agent, and felt that industrial water pollution was a crime against life on earth. His application of materials science to biological systems inspired other MIT colleagues to apply their expertise to living systems, paving the way for MIT to make a large commitment to bioengineering.

Markus Zahn is at the Department of Electrical Engineering and Computer Science and the Laboratory for Electromagnetic and Electronic Systems, Massachusetts Institute of Technology, 77 Massachusetts Ave., Room 10-174, Cambridge, Massachusetts 01239, USA.

e-mail:zahn@mit.edu 